\title{
Numerical Analysis of Heat Transfer and Fluid Flow in Multilayer Deposition of PAW-based Wire and Arc Additive Manufacturing
}

Xingwang Bai ${ }^{\mathrm{a},{ }^{*}}$, Paul Colegrove ${ }^{\mathrm{b}}$, Jialuo Ding ${ }^{\mathrm{b}}$, Xiangman Zhou ${ }^{\mathrm{c}}$, Chenglei Diao ${ }^{\mathrm{b}}$, Pillippe Bridgeman ${ }^{\mathrm{b}}$, Jan roman Hönnige ${ }^{\mathrm{b}}$, Haiou Zhang $^{\mathrm{d}}$, Stewart Williams ${ }^{\mathrm{b}}$

${ }^{a}$ School of Mechanical Engineering, University of South China, Hengyang, 421001, PR China

${ }^{\mathrm{b}}$ Welding Engineering and Laser Processing Centre, Cranfield University, Cranfield MK43 0AL, UK

${ }^{\mathrm{c}}$ School of Mechanical and Power Engineering, China Three Gorges University, Yichang 443002, China

${ }^{\mathrm{d}}$ School of Mechanical Science and Technology, Huazhong University of Science and Technology, Wuhan 430074, PR China

\begin{abstract}
:
A three-dimensional numerical model has been developed to investigate the fluid flow and heat transfer behaviors in multilayer deposition of plasma arc welding (PAW) based wire and arc additive manufacture (WAAM). The volume of fluid (VOF) and porosity enthalpy methods are employed to track the molten pool free surface and solidification front, respectively. A modified double ellipsoidal heat source model is utilized to ensure constant arc heat input in calculation in the case that molten pool surface dynamically changes. Transient simulations were conducted for the $1^{\text {st }}, 2^{\text {nd }}$ and $21^{\text {st }}$ layer depositions. The shape and size of deposited bead and weld pool were predicted and compared with experimental results. The results show that for each layer of deposition the Marangoni force plays the most important role in affecting fluid flow, conduction is the dominant method of heat dissipation compared to convection and radiation to the air. As the layer number increases, the length and width of molten pool and the width of deposited bead increase, whilst the layer height decreases. However these dimensions remain constant when the deposited part is sufficiently high. In high layer deposition, where side support is absent, the depth of the molten pool at the rear part is almost flat in the Y direction. The profile of the deposited bead is mainly determined by static pressure caused by gravity and surface tension pressure, therefore the bead profile is nearly circular. The simulated profiles and size dimensions of deposited bead and molten pool were validated with experimental weld appearance, cross-sectional images and process camera images. The simulated results are in good agreement with experimental results.
\end{abstract}

Keywords: Wire and arc additive manufacturing; Plasma arc welding; Numerical simulation; Molten pool

\section{Introduction}

Additive manufacturing (AM) is attracting increasing interest from academic and industrial communities due to the advantages of low production costs, short lead time and materials saving. AM technologies, especially 
those for metallic materials, have experienced striking advances over the last decade [1]. There are three main categories of AM processes which are based respectively on laser, electron beam and arc welding, and they have occupied different competitive positions for the direct manufacture of metallic parts [2-4]. Laser-based AM processes are capable of fabricating small parts with fine shape detail and lattice structures with high complexity; Electron-beam-based AM processes fabricate parts with high chemical purity; while arc-based AM process, i.e. wire and arc additive manufacture (WAAM), is characterized by a high deposition rate and low equipment costs [4]. WAAM utilizes metal wire as the feedstock, gas metal arc welding (GMAW), gas tungsten arc welding (GTAW) or plasma arc welding (PAW) as the heat source, and manipulation is done with either a robot or numerical control system. It is suitable for fabricating medium to large scale metal parts, including titanium structures for aerospace application. As the GMAW process of titanium is easily affected by arc wandering which results in increased surface roughness, GTAW or PAW are currently used for titanium deposition [5-6]. The higher energy density of PAW leads to a higher deposition rate and lower surface roughness [7].

One of the main requirements for automatic deposition is to know the shape and size of the deposited bead [8]. Bead modelling work using empirical models or artificial neural networks can establish the relationship between deposition parameters and bead shape [8-10]. The dependence of bead shape on thermal history and base surface condition are often ignored to save time in these studies. The deposited bead shape and size are a consequence of heat transfer and fluid flow in the molten pool. So an accurate bead prediction should combine experimental observation and fluid models. Numerical modelling of the molten pool can provide predictions, not only for molten pool shape and deposited bead shape, but also for the mass and heat transfer process, which is critical for understanding and control of the microstructure evolution of the deposited parts [11]. For most metal materials, coarse primary columnar grains are formed in the WAAM process [12-13], there is a big demand for a microstructure control method. Recently, the authors [14] developed a three-dimensional numerical model of an electric arc based on magnetic fluid dynamics for arc based additive forming process with pure argon shielding gas. The influence of base surface topographies on the deposited bead shape and the heat and mass transfer of electric arc were investigated in detail. However, to the best knowledge of the authors, computational fluid flow (CFD) modeling of the WAAM process is still in its infancy.

Despite much more complex deposition conditions and paths, the WAAM process has similar molten pool dynamics to conventional arc welding. There are a large number of studies devoted to CFD modeling of arc welding. Tanaka [15], Murphy[16] and Traidia [17] presented unified two-dimensional models for GTAW. Wang 
[18] developed a 3D unified model for double electrodes GTAW. Hu and Tsai [19-20] also developed a 3D unified model to study the transport phenomena including arc plasma, droplet generation, transfer and impingement, and the molten pool dynamics in GMAW. These unified models treat electrodes, plasma arc and molten pool in a whole model, providing more accurate results at higher computational cost. In contrast, the separated model is a more economical choice if the molten pool is of more interest in the simulation. In separated models, the free surface of the molten pool needs to be calculated through profile equilibrium method [21], VOF method [22-27], or Level-set method [28]. Empirical Gaussian distributions of heat flux and current density are often used on the free surface. So far, 3D separated molten pool models have been widely used for GMAW or GTAW to investigate groove welding [23], pulse welding [22, 26], humping formation [24], the ripple and crater formation [25-27], and other problems.

As for PAW, there are very limited numerical studies due to the higher physical complexity of the squeezed arc. Wang [29] developed a 3D transient model for PAW process using Level-set surface tracking and geometrydependent heat source and arc pressure distribution. Sun [30] used the molten pool surface deformation equation to calculate the real-time keyhole evolution in PAW process. Zhang [31] used VOF method to calculate the keyhole free surface. The coupling of the arc plasma, molten pool and keyhole are considered. Jiang [32] developed a unified axisymmetric model to quantitatively analyze the thermo-physical mechanisms in stationary keyhole PAW. Most of the above literature focuses on keyhole welding of plates. However, deep penetration and keyhole formation are avoided in the WAAM process as it causes excessive fluidity harmful for continuous deposition with potential for forming keyhole induced defects. So appropriate modifications have to be made to such models, in particular the heat source and arc pressure for the WAAM case. And considering the computational cost, the separated model is a more practical choice than unified model for the transient simulation of PAW-based WAAM process.

The thermo-physical behaviors of WAAM process are more complicated than those of conventional arc welding because the deposition conditions vary with each layer in terms of temperature history, cooling condition and base surface morphology. In this study, a three-dimensional numerical model was developed for analysis of heat transfer and fluid flow in multilayer deposition of PAW-based WAAM. Multilayer thin wall is the most common deposition style in WAAM. Transient simulations were conducted for the $1^{\text {st }}, 2^{\text {nd }}$ and $21^{\text {st }}$ layer depositions. Dynamic evolution of the molten pool surface was calculated, taking into account the effects of surface tension, Marangoni force, arc pressure, and arc shear stress. The shape and size of deposited bead 
and molten pool were predicted and compared with experimental results.

\begin{tabular}{|c|c|c|c|}
\hline \multicolumn{4}{|c|}{ Nomenclature } \\
\hline$A_{\text {mush }}$ & mushy zone constant, $\mathrm{kg} \cdot \mathrm{m}^{-3} \cdot \mathrm{s}^{-1}$ & $\mathbf{s}$ & vector tangent to the local free surface \\
\hline$A_{W}$ & cross-sectional area of wire, $\mathrm{m}^{2}$ & $S_{C}$ & mass source terms, $\mathrm{kg} \cdot \mathrm{m}^{-3} \cdot \mathrm{s}^{-1}$ \\
\hline$a_{g I} \sim a_{g 7}$ & coefficients used in arc shear stress mode & $T$ & Temperature, $\mathrm{K}$ \\
\hline$a_{1}$ & front ellipsoid radius of heat source model, $\mathrm{m}$ & $T_{L}$ & liquidus temperature of metal, $\mathrm{K}$ \\
\hline$a_{2}$ & rear ellipsoid radius of heat source model, $\mathrm{m}$ & $T_{S}$ & solidus temperature of metal, $\mathrm{K}$ \\
\hline$b$ & half width of heat source model, $\mathrm{m}$ & $T_{\text {ref }}$ & reference temperature, $\mathrm{K}$ \\
\hline$c$ & depth of heat source model, $\mathrm{m}$ & $T_{a m b}$ & ambient temperature, $\mathrm{K}$ \\
\hline$c_{p}$ & specific heat, $\mathrm{J} \cdot \mathrm{kg}^{-1} \cdot \mathrm{K}^{-1}$ & $t$ & time, $\mathrm{s}$ \\
\hline $\mathbf{F}_{\mathrm{g}}$ & body force, $\mathrm{N} \cdot \mathrm{m}^{-3}$ & $U$ & arc voltage, $\mathrm{V}$ \\
\hline $\mathbf{F}_{\text {ap }}$ & momentum source of arc pressure, $\mathrm{N} \cdot \mathrm{m}^{-3}$ & $x$ & $\mathrm{x}$-coordinate value, $\mathrm{m}$ \\
\hline $\mathbf{F}_{\text {as }}$ & momentum source of arc shear stress, $\mathrm{N} \cdot \mathrm{m}^{-3}$ & $x_{0}$ & $\mathrm{x}$-coordinate value of starting location, $\mathrm{m}$ \\
\hline $\mathbf{F}_{\mathrm{jb}}$ & momentum source of electromagnetic force, $\mathrm{N} \cdot \mathrm{m}^{-3}$ & & \\
\hline $\mathbf{F}_{\mathrm{ms}}$ & momentum source of enthalpy- porosity model, $\mathrm{N} \cdot \mathrm{m}^{-3}$ & $y$ & $\mathrm{y}$-coordinate value, $\mathrm{m}$ \\
\hline $\mathbf{F}_{\mathrm{ma}}$ & momentum source of Marangoni force, $\mathrm{N} \cdot \mathrm{m}^{-3}$ & $y_{0}$ & $\mathrm{y}$-coordinate value of starting location, $\mathrm{m}$ \\
\hline $\mathbf{F}_{\mathrm{st}}$ & momentum source of surface tension, $\mathrm{N} \cdot \mathrm{m}^{-3}$ & $z$ & z-coordinate value, $\mathrm{m}$ \\
\hline$F$ & volume fraction function of fluid & $z_{s}$ & $\mathrm{z}$ distance to free surface, $\mathrm{m}$ \\
\hline$F_{\text {arc }}$ & total arc force, $\mathrm{N} \cdot \mathrm{m}^{-3}$ & $z_{0}$ & $\mathrm{z}$-coordinate value of starting location, $\mathrm{m}$ \\
\hline$F_{j b x}$ & $\mathrm{x}$ component of electromagnetic force, $\mathrm{N} \cdot \mathrm{m}^{-3}$ & $\mathbf{V}$ & velocity vector, $\mathrm{m} \cdot \mathrm{s}^{-1}$ \\
\hline$F_{j b y}$ & y component of electromagnetic force, $\mathrm{N} \cdot \mathrm{m}^{-3}$ & $V_{T}$ & welding travelling speed, $\mathrm{m} \cdot \mathrm{s}^{-1}$ \\
\hline$F_{j b z}$ & $\mathrm{z}$ component of electromagnetic force, $\mathrm{N} \cdot \mathrm{m}^{-3}$ & $V_{W}$ & wire feeding speed, $\mathrm{m} \cdot \mathrm{s}^{-1}$ \\
\hline$f_{l}$ & liquid fraction & $V_{y}$ & y component of velocity vector, $\mathrm{m} \cdot \mathrm{s}^{-1}$ \\
\hline$g$ & acceleration of gravity, $\mathrm{m} \cdot \mathrm{s}^{-2}$ & Greeksy & abols \\
\hline$g_{a}$ & distribution function of arc shear stress & $B$ & thermal expansion coefficient, $1 \cdot \mathrm{K}^{-1}$ \\
\hline$h$ & enthalpy, $\mathrm{J} \cdot \mathrm{kg}^{-1}$ & $\gamma$ & surface tension coefficient, $\mathrm{N} \cdot \mathrm{m}^{-1}$ \\
\hline$h_{\text {conv }}$ & heat convection coefficient, $\mathrm{W} \cdot \mathrm{m}^{-2} \cdot \mathrm{K}^{-1}$ & $\partial \gamma / \partial T$ & surface tension temperature gradient, $\mathrm{N} \cdot \mathrm{m}^{-1} \cdot \mathrm{K}^{-1}$ \\
\hline$h_{\text {sum }}$ & combined heat transfer coefficient, $\mathrm{W} \cdot \mathrm{m}^{-2} \cdot \mathrm{K}^{-1}$ & $\varepsilon$ & radiation emissivity \\
\hline$\Delta H$ & latent heat of melting, $\mathrm{J} \cdot \mathrm{kg}^{-1}$ & $\varepsilon 0$ & a small number to prevent division by zero \\
\hline$I$ & deposition current, A & $\eta$ & arc heat efficiency \\
\hline$k$ & thermal conductivity, $\mathrm{W} \cdot \mathrm{m}^{-1} \cdot \mathrm{K}^{-1}$ & $\kappa$ & curvature of free surface, $1 \cdot \mathrm{m}^{-1}$ \\
\hline$k_{b}$ & Stefan-Boltzmann constant, $\mathrm{W} \cdot \mathrm{m}^{-2} \mathrm{~K}^{-4}$ & $\mu$ & Viscosity, $\mathrm{Pa} \cdot \mathrm{s}$ \\
\hline$L_{0}$ & thickness of base plate, $\mathrm{m}$ & $\mu_{m}$ & permeability, $\mathrm{H} \cdot \mathrm{m}^{-1}$ \\
\hline $\mathbf{n}$ & vector normal to the local free surface & $\pi$ & circumference ratio \\
\hline$p$ & pressure, $\mathrm{Pa}$ & $\rho$ & density, $\mathrm{kg} \cdot \mathrm{m}^{-3}$ \\
\hline$p_{s t}$ & surface tension pressure, $\mathrm{Pa}$ & $\rho_{0}$ & metal density at ambient temperature, $\mathrm{kg} \cdot \mathrm{m}^{-3}$ \\
\hline$p_{\text {arc }}$ & arc pressure, $\mathrm{Pa}$ & $\rho_{\text {gas }}$ & density of gas phase, $\mathrm{kg} \cdot \mathrm{m}^{-3}$ \\
\hline$q_{\text {arc }}$ & arc heat source, $\mathrm{W} \cdot \mathrm{m}^{-3}$ & $\rho_{\text {metal }}$ & density of metal phase, $\mathrm{kg} \cdot \mathrm{m}^{-3}$ \\
\hline$q_{\text {metal }}$ & energy of the feeding metal, $\mathrm{W} \cdot \mathrm{m}^{-3}$ & $\sigma_{p}$ & distribution of plasma arc pressure, $\mathrm{m}$ \\
\hline$P_{\max }$ & maximum of arc pressure, $\mathrm{Pa}$ & $\sigma_{j}$ & distribution of arc density, $\mathrm{m}$ \\
\hline$r$ & radius value of $X Y$ plane, $m$ & $\tau_{\max }$ & maximum of arc shear stress, $\mathrm{Pa}$ \\
\hline
\end{tabular}




\begin{tabular}{|llll|}
\hline$r_{d}$ & parameter used in arc shear stress model, $\mathrm{m}$ & $\hat{\boldsymbol{\tau}}$ & unit vector of arc shear stress \\
$\mathbf{r}$ & radius vector of XY plane, $\mathrm{m}$ & $\boldsymbol{\tau}_{\text {arc }}$ & arc shear stress, Pa \\
$R_{M}$ & radius of mass input spherical region, $\mathrm{m}$ & $\boldsymbol{\tau}_{\mathrm{ma}}$ & Marangoni shear stress, Pa \\
\hline
\end{tabular}

\section{Experimental procedure}

Titanium alloy (Ti-6Al-4V) parts were deposited using DC plasma power welder in an argon filled glove chamber as shown in Fig. 1. The motion of the torch was controlled by a numerical control program, and the shielding gas was pure argon. The nozzle diameter was $3.9 \mathrm{~mm}$, the tungsten electrode setback was $1.4 \mathrm{~mm}$ and the vertex angel was $45^{\circ}$.

The deposition process was monitored using a process camera (Xiris XVC-1000e) which was set to acquire images at a frequency of $25 \mathrm{~Hz}$. During deposition, the width and height of deposited bead were measured using a caliper and height gauge after each layer. After deposition, the cross-sections of the deposited parts were obtained with metallographic analysis and microscopic inspection. The characteristic dimensions of deposited bead and molten pool were measured based on images acquired by the camera and metallographic test.

The deposition parameters shown in Table 1 were used for both experiments and simulations. This set of parameters results in sound deposition in practical production. For better comparison, each layer deposition started at ambient temperature.

Table 1 Used deposition parameters

\begin{tabular}{ll}
\hline Parameters & Value(unit) \\
\hline Deposition welding current & $180 \mathrm{~A}$ \\
Deposition arc voltage & $23 \mathrm{~V}$ \\
Deposition welding speed & $300 \mathrm{~mm} / \mathrm{min}$ \\
Wire feeding rate & $2.2 \mathrm{~m} / \mathrm{min}$ \\
Plasma gas flow rate & $1 \mathrm{~L} / \mathrm{min}$ \\
Shielding gas flow rate & $15 \mathrm{~L} / \mathrm{min}$ \\
Ambient temperature & $300 \mathrm{~K}$ \\
Wire diameter & $1.2 \mathrm{~mm}$ \\
\hline
\end{tabular}




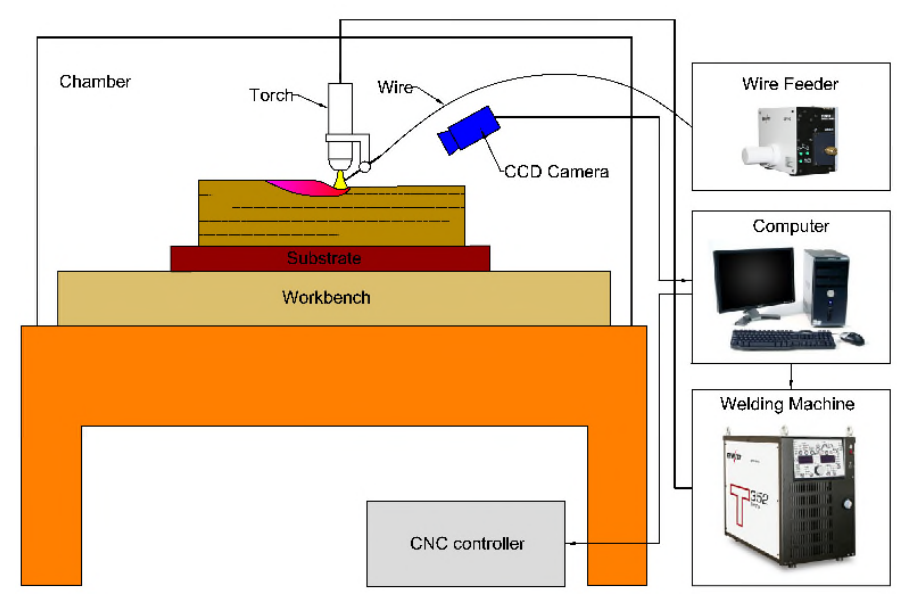

Fig. 1. Diagram of the experimental setup

\section{Mathematical models}

A three-dimensional numerical model was developed to investigate the heat and mass transfer in the molten pool of PAW-based WAAM process. As the molten pool and deposited bead are of main interest, the plasma arc and tungsten electrode were not included in the present model. The governing equations were solved using the FLUENT CFD code. The liquid metal was considered to be a Newtonian and incompressible fluid. The heat and mass loss caused by the liquid metal vaporization was ignored.

\subsection{Governing equations}

The geometry model of computational domain is shown in Fig. 2. The VOF method was used to track the dynamic gas-metal interface, i.e., the free surface of molten pool and solidified bead. Initially, the lower part is filled with metal which represents the base plate. The following governing equations are calculated in the whole domain.

Continuity equation:

$$
\frac{\partial \rho}{\partial t}+\nabla \cdot(\rho \mathbf{V})=S_{c}
$$

Momentum conservation equation:

$$
\frac{\partial}{\partial t}(\rho \mathbf{V})+\nabla \cdot(\rho \mathbf{V V})=-\nabla p+\nabla \cdot(\mu \nabla \mathbf{V})+\mathbf{F}_{\mathrm{ms}}+\mathbf{F}_{\mathrm{g}}+\mathbf{F}_{\mathrm{jb}}+\mathbf{F}_{\mathrm{st}}+\mathbf{F}_{\mathrm{ap}}+\mathbf{F}_{\mathrm{ma}}+\mathbf{F}_{\mathrm{as}}
$$

Energy conservation equation:

$$
\frac{\partial}{\partial t}(\rho h)+\nabla \cdot(\mathbf{V} \rho h)=\nabla \cdot(k \nabla T)+q_{\text {arc }}+q_{\text {metal }}+q_{\text {loss }}
$$

VOF conservation equation: 


$$
\frac{\partial F}{\partial t}+(\mathbf{V} \cdot \nabla) F=0
$$

Two-phase (argon and titanium alloy) flow model was used. In this case, volume fraction function $F=1$ corresponds to cells full of metal fluid, while $F=0$ corresponds to cells empty of metal fluid. Cells with $F$ lying between 0 and 1 are located in the free surface. The gradient direction of $F$ is the normal direction of free surface.

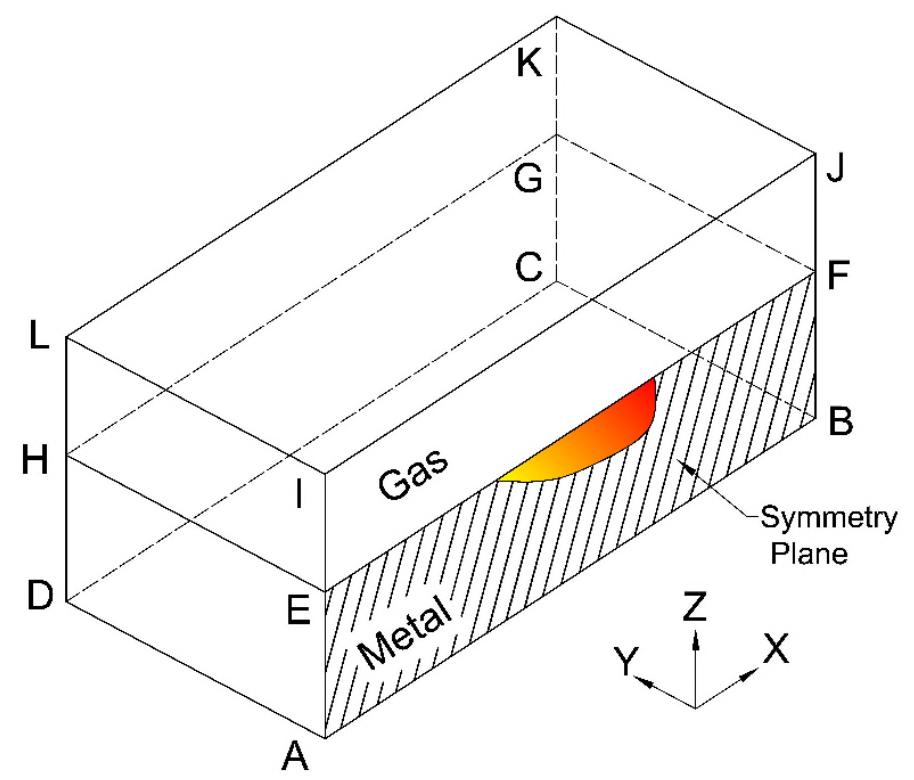

Fig. 2. Schematic of geometry model for simulations

\subsection{Phase change model}

The enthalpy-porosity technique [33] was applied to model the solid-liquid mushy zone as a porous medium with porosity equal to the liquid fraction. The liquid fraction was used to implicitly track the solid-liquid interface. This technique treats mushy zone as porous region, the porosity equals liquid volume fraction $f_{l}$. Liquid fraction between solidus and liquidus points is assumed to vary linearly with temperature.

$$
f_{l}=\left\{\begin{array}{cc}
0 & \left(T \leq T_{S}\right) \\
\frac{T-T_{S}}{T_{L}-T_{S}} & \left(T_{S}<T<T_{L}\right) \\
1 & \left(T \geq T_{L}\right)
\end{array}\right.
$$

A source term was added to momentum equation to extinguish the velocities in the mushy zone and fully solidified region.

$$
\mathbf{F}_{m s}=A_{m u s h y} \frac{\left(1-f_{l}^{2}\right)}{\left(f_{l}^{3}+\varepsilon_{0}\right)} \mathbf{V}
$$

where $\varepsilon_{0}$ is a small number $(0.001)$ to prevent division by zero; $A_{m u s h y}$ is the mushy zone constant which 
determines how fast the velocity drops to zero as the material solidifies. Values between $10^{4}$ and $10^{7}$ are recommended by the FLUENT for most computations. In the present study, through trial and error, an $A_{m u s h y}$ of about $2 \times 10^{6}$ is used to achieve both fast velocity drop and convergent computation.

Meanwhile, the latent heat $\Delta H$ related with phase change was taken into account as enthalpy in the energy equation and was calculated as follows.

$$
h=c_{p} T+f_{l} \Delta H
$$

\subsection{Body forces}

The body forces exerted in the metal region include gravity, buoyancy force and electromagnetic force. The Boussinesq approximation was employed to consider buoyance force. The momentum source term for gravity and buoyancy force can be expressed as follows.

$$
\mathbf{F}_{g}=\rho \mathbf{g}-\rho \beta\left(T-T_{L}\right) \mathbf{g}
$$

The simplified equations [34] were used in the present study to calculate the three components of electromagnetic force $\mathbf{F}_{\mathrm{jb}}$. It should be noted that Eq. (9) is written in the workpiece coordinate frame rather than the arc coordinate frame. The location $\left(x_{0}, y_{0}, z_{0}\right)$ is the starting point of each layer deposition. When using a welding current of $180 \mathrm{~A}$, the maximum components are in the order of $10^{4} \mathrm{~N} / \mathrm{m}^{3}$. The overall effect of the electromagnetic force is to drive the liquid at the center of molten pool downwards.

$$
\begin{aligned}
& F_{j b x}=-\frac{\mu_{m} I^{2}}{4 \pi^{2} \sigma_{j}^{2} r} \exp \left(-\frac{r^{2}}{2 \sigma_{j}^{2}}\right)\left[1-\exp \left(-\frac{r^{2}}{2 \sigma_{j}^{2}}\right)\right]\left(1-\frac{z}{L_{0}}\right)^{2} \frac{\left(x-x_{0}-V_{T} t\right)}{r} \\
& F_{j b y}=-\frac{\mu_{m} I^{2}}{4 \pi^{2} \sigma_{j}^{2} r} \exp \left(-\frac{r^{2}}{2 \sigma_{j}^{2}}\right)\left[1-\exp \left(-\frac{r^{2}}{2 \sigma_{j}^{2}}\right)\right]\left(1-\frac{z}{L_{0}}\right)^{2} \frac{\left(y-y_{0}\right)}{r} \\
& F_{j b z}=\frac{\mu_{m} I^{2}}{4 \pi^{2} \sigma_{j}^{2} r} \exp \left(-\frac{r^{2}}{2 \sigma_{j}^{2}}\right)\left(1-\frac{z-z_{0}}{L_{0}}\right) \\
& \text { where } r=\sqrt{\left(x-x_{0}-V_{T} t\right)^{2}+\left(y-y_{0}\right)^{2}}
\end{aligned}
$$

\subsection{Driving Forces on free surface}

The driving forces on the free surface of the molten pool include surface tension, Marangoni force, arc pressure and arc shear stress. In the PAW process, these four forces play critical roles in affecting the shape of the free surface and the flow pattern in molten pool. The calculation accuracy is related with the accuracy of 
interface tracking. According to the VOF algorithm, the interface is determined by tracking cells with volume fraction between 0 and 1 . This implicit interface is not a real boundary of computational domain. Hence, all forces on the free surface should be interpreted as continuous volumetric force terms.

The surface tension pressure normal to the free surface can be expressed as:

$$
p_{s t}=\gamma \kappa
$$

The Marangoni shear stress is calculated as follows:

$$
\boldsymbol{\tau}_{\mathrm{ma}}=\frac{\partial \gamma}{\partial T} \frac{\partial T}{\partial \mathbf{s}}
$$

In GTAW simulations, the arc pressure is often approximated as Gaussian density distribution. The peak pressure and distribution parameter are related with welding current and electrode tip angle.

$$
p_{\text {arc }}=\frac{F_{\text {arc }}}{2 \pi \sigma_{p}^{2}} \exp \left(-\frac{r^{2}}{2 \sigma_{p}^{2}}\right)=P_{\max } \exp \left(-\frac{r^{2}}{2 \sigma_{p}^{2}}\right)
$$

In advance of this work, the arc pressures were measured through the small-hole method. In this method, a thick water cooled copper plate was used as the anode. In the center of anode there was a $0.3 \mathrm{~mm}$ diameter hole through which the arc pressure was measured with a pressure sensor. The measuring procedure is similar to the method in reference [35]. The measured results show that although the arc pressure acting on the free surface is much larger than that in GTAW, the arc pressure can still be approximated as a Gaussian density distribution for simplicity. Fig. 3 presents the comparison of the measured data and the Gaussian distribution used in our simulation. The peak pressure $1650 \mathrm{~Pa}$ and the distribution parameter $0.78 \mathrm{~mm}$ were obtained through nonlinear curve fitting based on experimental data.

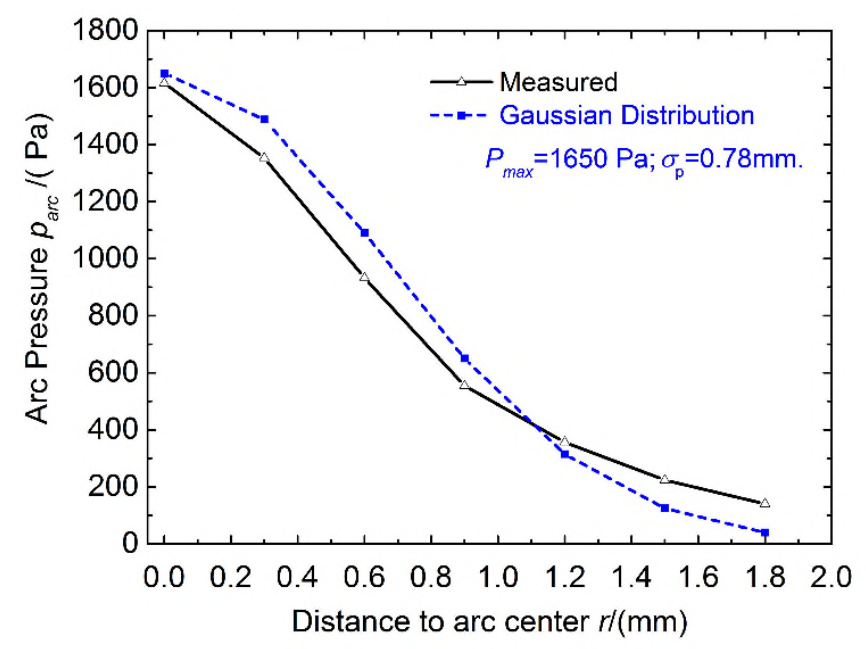

Fig.3 The arc pressure value used in simulations 
Arc shear stress is a drag force caused by the arc plasma moving radially outwards on the molten pool surface. Arc shear stress is a function of the dynamic viscosity and radial velocity of the shielding gas. As the welding speed is low in the WAAM process and plasma velocity is very high, the arc shear stress is assumed to have an axisymmetric distribution. An empirical axisymmetric distribution was employed in the study.

$$
\begin{gathered}
\boldsymbol{\tau}_{a r c}=\tau_{\max } g_{a}(r) \hat{\boldsymbol{\tau}} \\
g_{a}(r)=\left\{\begin{array}{cc}
a_{g 1} r^{3}+a_{g 2} r^{2}+a_{g 3} r+a_{g 4} & \left(r \leq r_{d}\right) \\
a_{g 5} \exp \left(-\frac{r}{a_{g 6}}\right)+a_{g 7} & \left(r>r_{d}\right)
\end{array}\right. \\
\hat{\boldsymbol{\tau}}=\frac{\mathbf{r}-\mathbf{n}(\mathbf{r}\lceil\mathbf{n})}{\mid \mathbf{r}-\mathbf{n}(\mathbf{r}\lceil\mathbf{n}) \mid}
\end{gathered}
$$

For simplicity, the coefficients $a_{g l} \sim a_{g 7}$ and $r_{d}$ in reference [35] were used in the study. The peak arc shear stress was estimated to be about $80 \mathrm{~Pa}$ according the analytical deduction method presented in reference [36]. The arc shear stress has an axisymmetric distribution, which is acceptable as the welding speed is low and plasma velocity is very high in the WAAM process. It should be noted that the dependency of arc pressure and arc shear stress on surface deformation was ignored in this study.

Using the continuum surface force [37] method, the surface forces in the normal direction such as surface tension and arc pressure can be reformulated as volumetric force terms as follows.

$$
\begin{aligned}
& \mathbf{F}_{s t}=p_{s t} \nabla F \frac{F \rho_{\text {metal }}+(1-F) \rho_{\text {gas }}}{\frac{1}{2}\left(\rho_{\text {metal }}+\rho_{\text {gas }}\right)} \\
& \mathbf{F}_{a p}=p_{\text {arc }} \nabla F \frac{F \rho_{\text {metal }}+(1-F) \rho_{\text {gas }}}{\frac{1}{2}\left(\rho_{\text {metal }}+\rho_{\text {gas }}\right)}
\end{aligned}
$$

Surface shear forces such as Marangoni force and arc shear stress can be reformulated as follows.

$$
\begin{gathered}
\mathbf{F}_{m a}=\boldsymbol{\tau}_{m a}|\nabla F| \frac{F \rho_{\text {metal }}+(1-F) \rho_{\text {gas }}}{\frac{1}{2}\left(\rho_{\text {metal }}+\rho_{\text {gas }}\right)} \\
\mathbf{F}_{a s}=\boldsymbol{\tau}_{\text {arc }}|\nabla F| \frac{F \rho_{\text {metal }}+(1-F) \rho_{\text {gas }}}{\frac{1}{2}\left(\rho_{\text {metal }}+\rho_{\text {gas }}\right)}
\end{gathered}
$$




\subsection{Mass input model}

Unlike the GMAW process where metal droplets impinge onto the molten pool with a large velocity, the typical scenario of PAW is that the wire touches molten pool during deposition, the wire is melted and flows into molten pool at a comparatively low velocity. In the present study, the mass feeding process was modeled as a source term in a spherical region at a specific location. The location was determined according to the actual experimental setup. As mentioned above, side direction wire feeding was used, the mass input position was $3 \mathrm{~mm}$ behind the arc center. According to the camera observation of the wire melting and transfer to the molten pool, the spherical region was chosen to be $0.6 \mathrm{~mm}$ radius, the initial velocity was about $0.1 \mathrm{~m} / \mathrm{s}$ in the negative $\mathrm{Z}$ direction. And the temperature was chosen to be $2600 \mathrm{~K}$ according to the results in literature [29-31].

If the mass loss due to evaporation is ignored, the source terms of mass can be written as

$$
\begin{gathered}
S_{c}=\rho_{0} \frac{A_{W} V_{W}}{4 / 3 \pi R_{M}^{3}} \\
q_{\text {metal }}=S_{C}\left(\Delta H+\int_{T_{\text {ref }}}^{2600} c_{p} d T\right)
\end{gathered}
$$

where $\rho_{0}$ is the density at ambient temperature, $A_{W}$ is the cross-sectional area of the wire, $V_{W}$ is the wire feeding speed, $R_{M}$ is the radius of the spherical region.

\subsection{Arc heat source model}

According to reference [38], the arc heat efficiency is estimated to be about 0.53 for the case of this study. Then the heat of arc heat source model can be written as Eq. (23). The second term on the right hand of Eq. (23) is the heat of melting metal wire.

$$
Q_{a r c}=\eta U I-4 / 3 \pi R_{M}^{3} q_{\text {metal }}
$$

Studies [31-32] show that a combined double-ellipsoidal and conical volumetric heat source produce results that agree with experiments better if the keyhole effect cannot be ignored. As stated earlier, deep keyholes are avoided in the PAW-based WAAM process to ensure the success of deposition. Therefore, a modified doubleellipsoidal volumetric heat source model was employed in the present study. 


$$
q_{a r c}(x, y, z)= \begin{cases}\frac{12 \sqrt{3} Q_{a r c}}{\left(a_{1}+a_{2}\right) b c \pi} \exp \left(-\frac{3\left(x-x_{0}-V_{T} t\right)^{2}}{a_{1}^{2}}-\frac{3\left(y-y_{0}\right)^{2}}{b^{2}}-\frac{3 z_{s}^{2}}{c^{2}}\right) \quad\left(x-x_{0}-V_{T} t>0\right) \\ \frac{12 \sqrt{3} Q_{a r c}}{\left(a_{1}+a_{2}\right) b c \pi} \exp \left(-\frac{3\left(x-x_{0}-V_{T} t\right)^{2}}{a_{2}^{2}}-\frac{3\left(y-y_{0}\right)^{2}}{b^{2}}-\frac{3 z_{s}^{2}}{c^{2}}\right) \quad\left(x-x_{0}-V_{T} t \leq 0\right)\end{cases}
$$
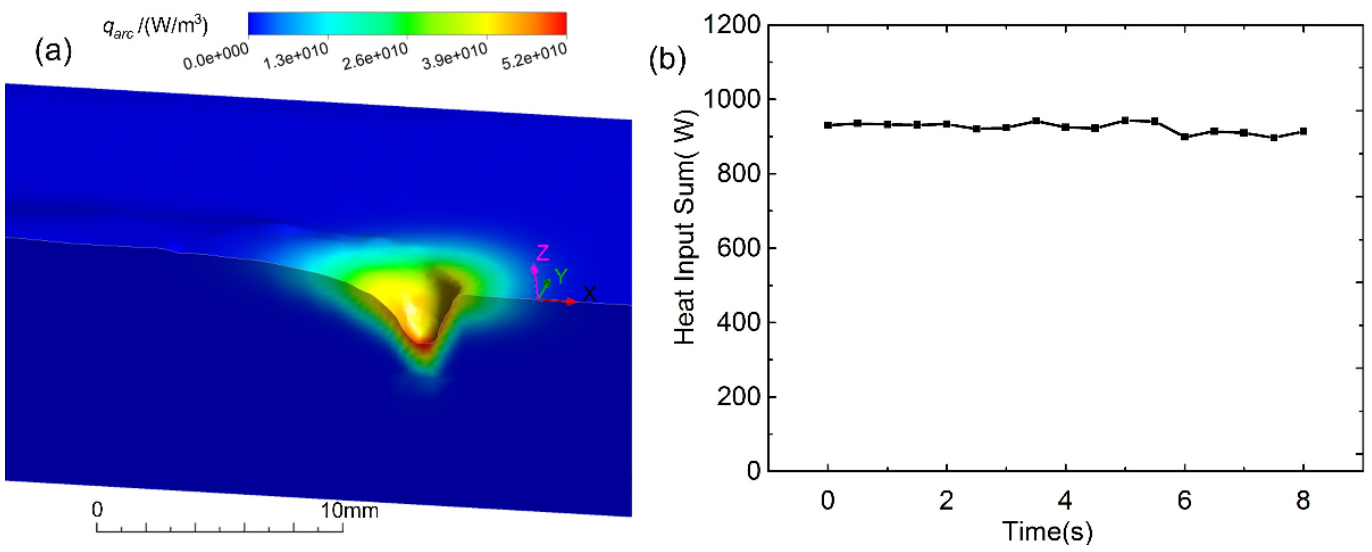

Fig.4 The adaptive double-ellipsoidal heat source model: (a) an example of distribution; (b) the variation of total heat input during the $1^{\text {st }}$ layer deposition.

It should be noted that Eq. (24) is written in the workpiece coordinate frame. The point $\left(x_{0}+V_{T} t, y_{0}, z_{0}\right)$ is the current location of arc bottom center. The distribution parameters $a_{1}, a_{2}, b$ and $c$ were determined using the method presented in previous work [38]. Considering the free surface is highly deformed, the modified heat source equation Eq. (23) uses $z_{s}$, the distance to interface in the $\mathrm{Z}$ direction, instead of fixed $\mathrm{Z}$ coordinate. Fig.4 (a) shows a typical case of arc heat distribution in which the free surface is obviously curved. It can be found that the modified heat source model is actually a volumetric reformulation of double elliptic surface heat source. In the simulation for the $1^{\text {st }}$ layer deposition, the total heat input power was calculated by integrating heat input density in the whole volume, and is shown in Fig. 4(b). The result shows that the total heat input remains constant during deposition regardless of the dynamically varying surface shape of molten pool. This heat source model shows better adaptability to a deformed free surface than the conventional double ellipsoidal heat source model.

\subsection{Boundary conditions}

The boundary conditions used in the present study are listed in Table 2.

Table 2 Boundary conditions

\begin{tabular}{llll}
\hline Boundary & Type & Momentum & Energy \\
\hline ABCD, DAEH, CDHG, BCGF & Wall & V=0 & Eq. (24) \\
\hline
\end{tabular}




IJKL, HEIL, GHLK, FGKJ Pressure outlet Atmosphere Pressure T=300K

\begin{tabular}{|c|c|c|c|}
\hline ABJI & Symmetry & $V_{u}=0, \quad \partial \mathbf{V} / \partial n=0$ & $\partial T / \partial n=0$ \\
\hline
\end{tabular}

The convection and radiation boundary conditions were used to describe heat loss of external boundaries.

$$
\begin{array}{r}
-k \frac{\partial T}{\partial \mathbf{n}}=h_{\text {sum }}\left(T-T_{\text {amb }}\right) \\
h_{\text {sum }}=h_{\text {conv }}+\varepsilon k_{b} \frac{\left(T^{4}-T_{\text {amb }}{ }^{4}\right)}{\left(T-T_{a m b}\right)}
\end{array}
$$

It should be noted that convection and radiation also occurred on free surface. The corresponding heat loss can be reformulated as volumetric heat source using continuum surface force method [37].

$$
q_{\text {loss }}=h_{\text {sum }}\left(T-T_{\text {amb }}\right)|\nabla F| \frac{F \rho_{\text {metal }}+(1-F) \rho_{\text {gas }}}{\frac{1}{2}\left(\rho_{\text {metal }}+\rho_{\text {gas }}\right)}
$$

The material used for the wire and base plate is Ti-6Al-4V. The detailed values of thermo-physical properties and other physical variables used in this study are listed in Table 3.

Table 3 Thermo-physical properties of Ti-6Al-4V and other physical variables

\begin{tabular}{ll}
\hline Property, (unit) & Value \\
\hline Solidus temperature, $(\mathrm{K})$ & $1878[40]$ \\
Liquidus temperature, $(\mathrm{K})$ & $1928[40-41]$ \\
Density at ambient temperature, $\left(\mathrm{kg} \mathrm{m}^{-3}\right)$ & $4420[41]$ \\
Specific heat of solid metal, $\left(\mathrm{J} \mathrm{kg}^{-1} \mathrm{~K}^{-1}\right)$ & temperature-dependent[41] \\
Thermal conductivity of solid metal, $\left(\mathrm{W} \mathrm{m}^{-1} \mathrm{~K}^{-1}\right)$ & temperature-dependent[41] \\
Viscosity, $(\mathrm{Pa} \cdot \mathrm{s})$ & $0.005[40]$ \\
Thermal expansion coefficient, $\left(\mathrm{K}^{-1}\right)$ & $8 \times 10^{-6}[40]$ \\
Surface tension at liquidus temperature, $\left(\mathrm{Nm}^{-1}\right)$ & $1.33[42]$ \\
Temperature coefficient of surface tension, $\left(\mathrm{Nm}^{-1} \mathrm{~K}^{-1}\right)$ & $-0.26 \times 10^{-3}[42]$ \\
Latent heat of melting, $\left(\mathrm{J} \mathrm{kg}^{-1}\right)$ & $2.85 \times 10^{5}[41]$ \\
Emissivity & temperature-dependent[41] \\
Convective heat transfer coefficient, $\mathrm{Wm}^{-2} \mathrm{~K}^{-1}$ & 15 \\
Atmospheric pressure, $\left(\mathrm{Nm}{ }^{-2}\right)$ & 101300 \\
Stefan-Boltzmann constant, $\left(\mathrm{Wm}^{-2} \mathrm{~K}^{-4}\right)$ & $5.67 \times 10^{-8}$ \\
\hline
\end{tabular}

\section{Numerical considerations}


Due to the geometric symmetry, the mesh model included only half of the base metal on positive Y side. The computational domain covered the range of $0 \leq x \leq 60 \mathrm{~mm}, 0 \leq \mathrm{y} \leq 15 \mathrm{~mm},-10 \leq \mathrm{z} \leq 5 \mathrm{~mm}$ (exceptionally, the $\mathrm{z}$ range was $-10 \leq \mathrm{z} \leq 25 \mathrm{~mm}$ in the simulation for $21^{\text {st }}$ layer deposition). Hexahedral grids of non-uniform size were used with finer grid sizes near the high temperature region and free surface region. The minimum grid size was 0.25 $\mathrm{mm}$.

The governing equations were solved using the commercial CFD code FLUENT. The improved SIMPLE algorithm, namely, the PISO algorithm was used to treat the pressure-velocity coupling. The Body Force Weighted method was applied to discretize the pressure equation, and the Second Order Upwind method was applied to discretize the equations of momentum and energy. Explicit VOF formulation and Geo-reconstruct interpolation scheme were adopted for accurate interface tracking. The time step was set as $5 \times 10^{-5} \mathrm{~s}$. It took about $72 \mathrm{~h}$ to simulate $8 \mathrm{~s}$ real time of deposition using high performance computer of $48 \times 1.6 \mathrm{GHz} \mathrm{CPU}$.

\section{Results and discussions}

\subsection{Results of $1^{\text {st }}$ layer deposition}

The $1^{\text {st }}$ layer deposition is a bead-on-plate scenario. As shown in Fig. 5, the morphology of the molten pool is developing during the beginning stage from $0 \mathrm{~s}$ to $2 \mathrm{~s}$. The shape and temperature of molten pool and deposited bead evolve gradually as time increases. As the welding parameters and traveling speed are constant, the shape and size of molten pool do not change much after $2 \mathrm{~s}$, the molten pool reaches a quasi-steady state if viewed in arc coordinate system. The peak temperature occurs at mass input location (wire feeding) which is $3 \mathrm{~mm}$ behind the arc center.
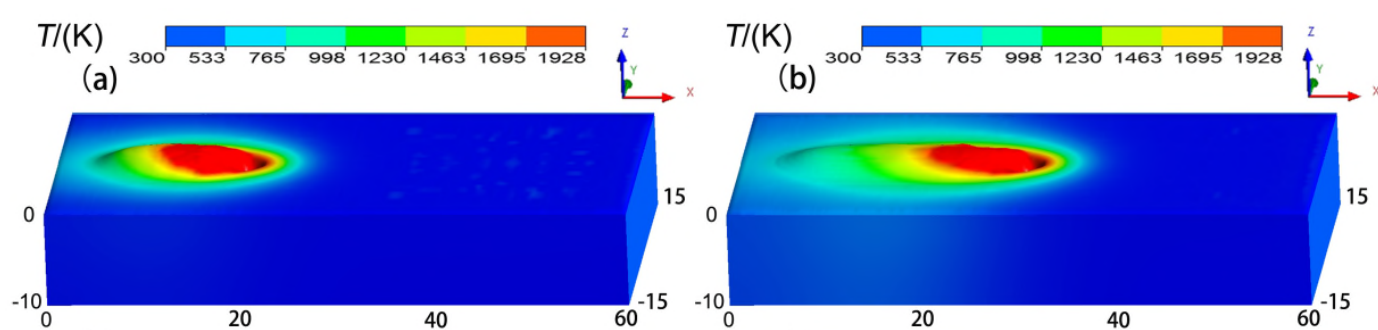

(c)

(d)
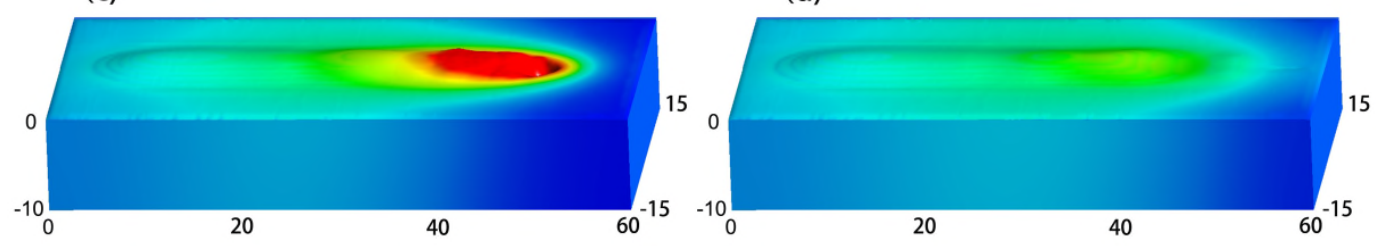

Fig.5. 3D views of molten pool and deposited bead during the $1^{\text {st }}$ layer deposition at different time: 


$$
\text { (a) } t=2.0 \mathrm{~s} \text {; (b) } t=4.0 \mathrm{~s} \text {; (c) } t=8.0 \mathrm{~s} \text {; (d) } t=10.0 \mathrm{~s} \text {. }
$$

In the keyhole PAW process, the arc force is so strong that the depression can even penetrate thin base plate and lead to a keyhole. Key-hole is generally avoided in PAW-based WAAM process because they result in deposition defects. In the present study, the deposition parameters shown in Table 1 result in relatively small arc forces. The free surface of molten pool is depressed under the effects of arc forces and electromagnetic forces, forming a "blind key-hole", in other word, a depressed region during $1^{\text {st }}$ layer deposition. As shown in Fig.6 and Fig. 7(a), the depressed region is about $2.2 \mathrm{~mm}$ deep at the lowest position. Almost no liquid layer can be found on the front slope due to the quick movement of liquid by arc forces. The arc forces move the liquid backward as soon as the arc heat melts metal ahead of the arc. The arc forces, including both arc pressure and shear stress, act as a driving force to form a depressed region, while surface tension acts to prevent the free surface from depressing. When the arc extinguishes at $t=8 \mathrm{~s}$, the last depressed region is not fully filled by backflow of molten pool, thereby leaving a crater at the termination of deposited bead as shown in Fig.5(d).

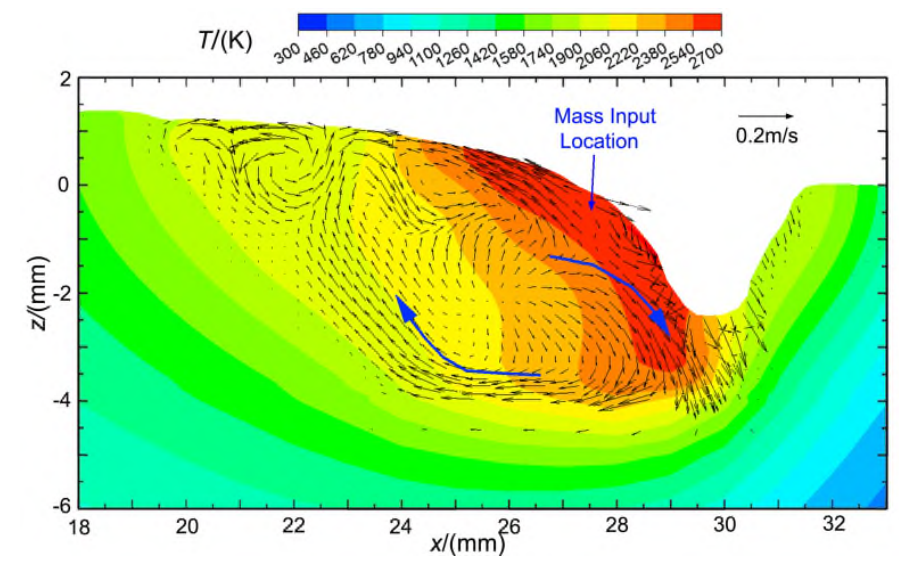

Fig.6. Temperature and fluid flow field on the longitudinal cross-section $(y=0)$ at $t=4 \mathrm{~s}$ of the $1^{\text {st }}$ layer deposition.

As shown in Fig.6, a clockwise circulation is formed in molten pool behind the arc under the combined effect of arc pressure, arc shear stress, surface tension, Marangoni force, electromagnetic force and gravity, which have progressively decreasing levels of influence. As the molten pool is surrounded and supported by the base plate, the influence of gravity and buoyancy are comparatively small. On the back slope of depressed region, there are two forces exerting contrary effects. The arc shear stress is driving outward flow from the valley center, while the Marangoni force is driving downward flow as the temperature is higher at the mass input location than valley center. In the studied case, the peak of arc shear stress is estimated to be about $80 \mathrm{~Pa}$ [36], while the maximum Marangoni force is estimated to be above $400 \mathrm{~Pa}$ according to the calculation. So the Marangoni 
force dominates the surface flow on the back slope. The main flow pattern is metal liquid flows downward from mass input location to valley on the surface and flow backward inside the molten pool, thereby forming a clockwise main flow pattern. The main flow pattern is indicated by the bold blue arrow in Fig.6. Meanwhile, in the rear of molten pool, small turbulences exist due to the collision between the flow driven by Marangoni force and reflection flow by solidification front.

Fig. 7 shows the temperature and fluid flow field at different transverse cross-sections. With farther distance to arc center, the cross-section has lower temperature, smaller molten pool and larger weld reinforcement. Analyzing Fig. 7(b) which corresponds to the cross-section at $\mathrm{x}=26 \mathrm{~mm}, 4 \mathrm{~mm}$ behind the arc center, it can be found that metal liquid flow is upward inside and outward on the surface. This indicates that Marangoni force dominates the flow direction on $\mathrm{YZ}$ plane.
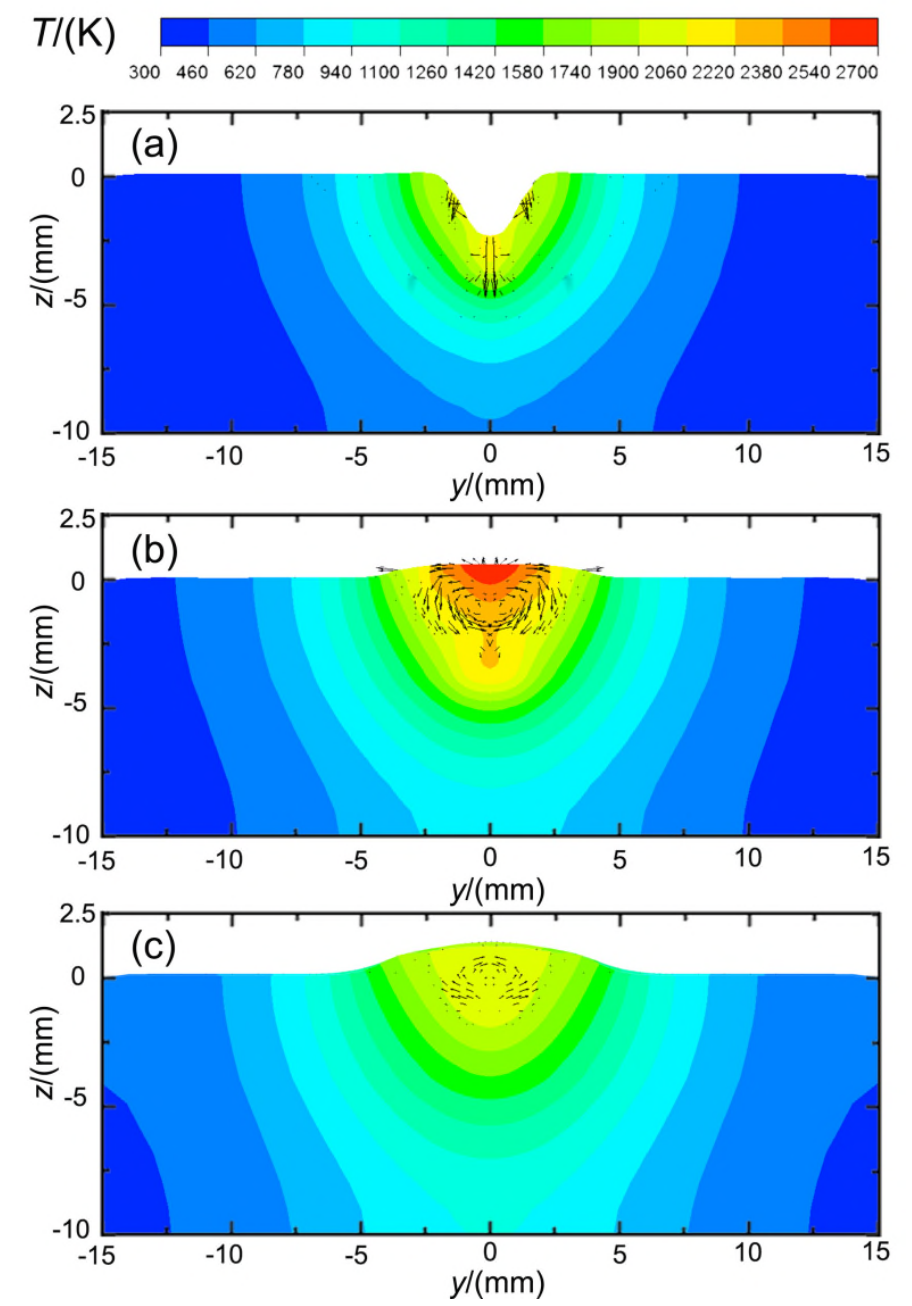

. Fig.7. Temperature profiles at $t=4 \mathrm{~s}$ of the $1^{\text {st }}$ layer deposition on different transverse cross-sections:

(a) $x=30 \mathrm{~mm}$ (current arc center location); (b) $x=26 \mathrm{~mm}$; (c) $x=22 \mathrm{~mm}$. 


\subsection{Results of $2^{\text {nd }}$ layer deposition}

Unlike the $1^{\text {st }}$ layer which is deposited on a flat base plate, the $2^{\text {nd }}$ layer is deposited on the resultant bead of $1^{\text {st }}$ layer deposition, which is a convex surface. With less support from two sides, the molten pool tends to flow downward on both sides, resulting in a larger width. Comparing Fig. 7 and Fig. 10, it is obvious that the $2^{\text {nd }}$ layer deposition has larger widths of molten pool and deposited bead than the $1^{\text {st }}$ layer.
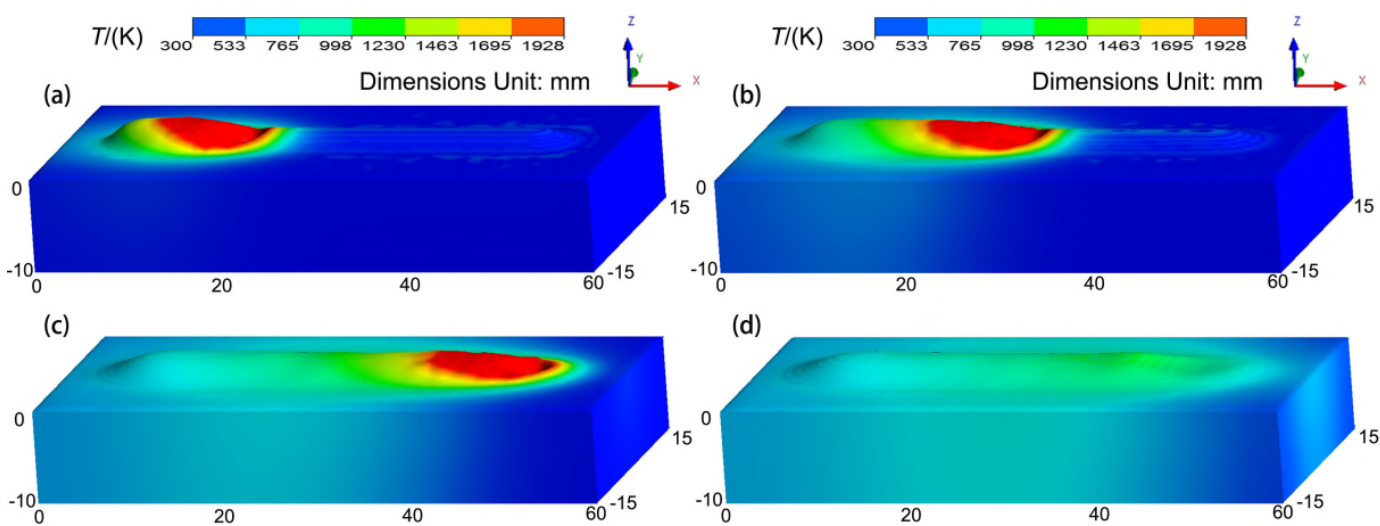

Fig.8. 3D views of molten pool and deposited bead during the $2^{\text {nd }}$ layer deposition at different time:

(a) $t=2.0 \mathrm{~s}$; (b) $t=4.0 \mathrm{~s}$; (c) $t=8.0 \mathrm{~s} ;$ (d) $t=10.0 \mathrm{~s}$.

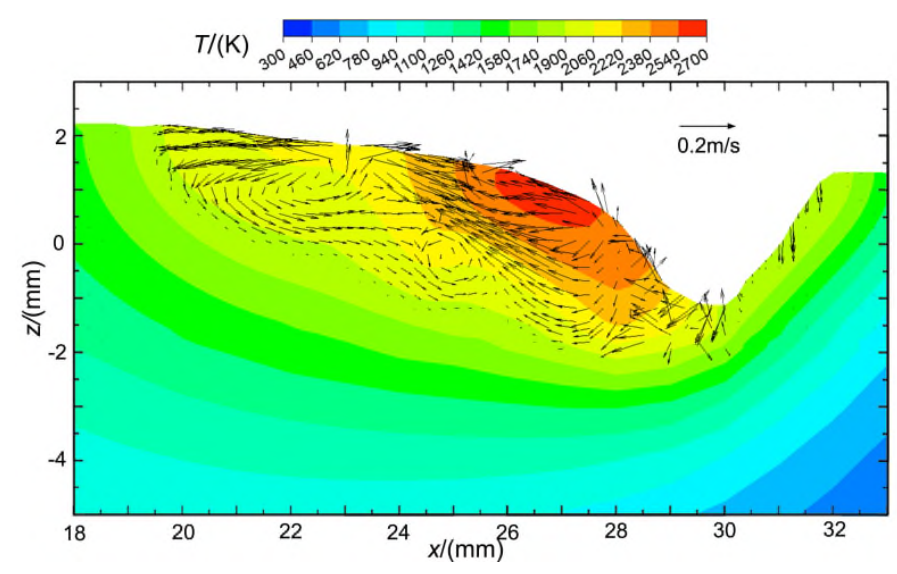

Fig.9. Temperature and fluid flow field on the longitudinal cross-section $(y=0)$ at $t=4 \mathrm{~s}$ of the $1^{\text {st }}$ layer deposition.

Comparing Fig. 9 with Fig. 6, it can be found that the molten pool of the $2^{\text {nd }}$ layer has similar flow field with the $1^{\text {st }}$ layer in terms of fluid velocity and flow direction. The main flow pattern is still in clockwise direction with flow dominated by Marangoni forces. However, since the arc heat is always concentrated on the top face, the larger height results in longer heat dissipation path. Therefore the length of molten pool is slightly larger than the $1^{\text {st }}$ layer. As shown in Fig. 9 and Fig. 10(a), the molten pool is depressed in the center due to the 
arc force. The depressed region has slightly larger open and smaller depth compared with $1^{\text {st }}$ layer due to less side support.
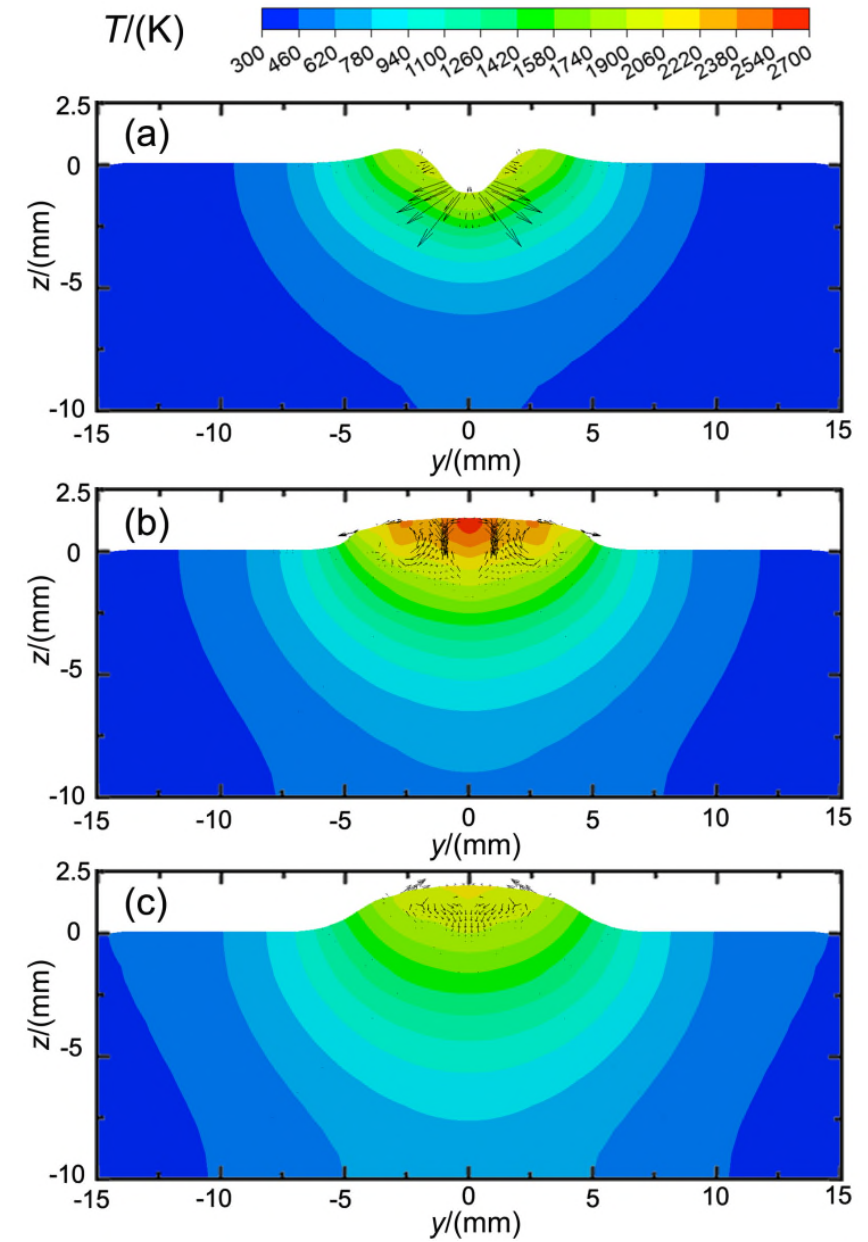

Fig.10. Temperature profiles at $t=4 \mathrm{~s}$ of the $2^{\text {nd }}$ layer deposition on different transverse cross-sections:

(a) $x=30 \mathrm{~mm}$ (current arc center location); (b) $x=26 \mathrm{~mm}$; (c) $x=22 \mathrm{~mm}$.

\subsection{Results of $21^{\text {st }}$ layer deposition}

Because the simulation for 20 layers of continuous deposition is too time-consuming, the simulation for $21^{\text {st }}$ layer deposition is initialized with the real bead profile of $20^{\text {th }}$ layer which is obtained through cross-sectional measurement. Fig.11 shows a typical view of molten pool and deposited bead during deposition. Comparing Fig. 11 with Fig 5 (b) and Fig. 8 (b), it can be seen that the molten pool of the $21^{\text {st }}$ layer has a larger length than the $1^{\text {st }}$ and $2^{\text {nd }}$ layer. In simulation results, the length of molten pool is about $16 \sim 17 \mathrm{~mm}$ for the $21^{\text {st }}$ layer, while the length is about $10 \sim 11 \mathrm{~mm}$ for the $1^{\text {st }}$ and $2^{\text {nd }}$ layers. The larger molten pool can be attributed to the reduced heat dissipation. Heat dissipation is reduced when deposition height increases due to the smaller amount of 
surrounding material which acts as a heat sink and thermal conduction channel.

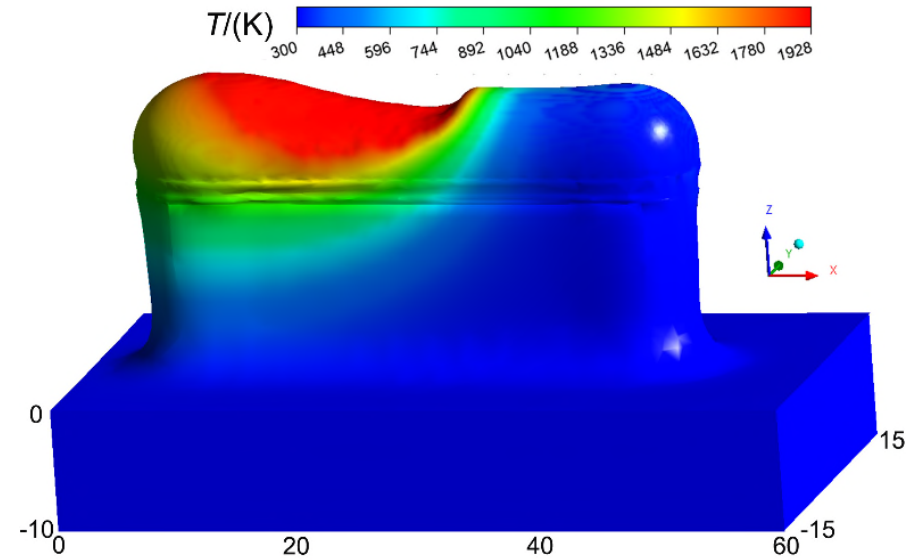

Fig.11. 3D view of molten pool and deposited bead at $t=4.0 \mathrm{~s}$ of the $21^{\text {st }}$ layer deposition.

$T /(\mathrm{K})$

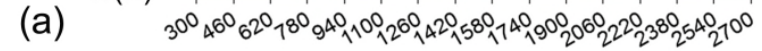

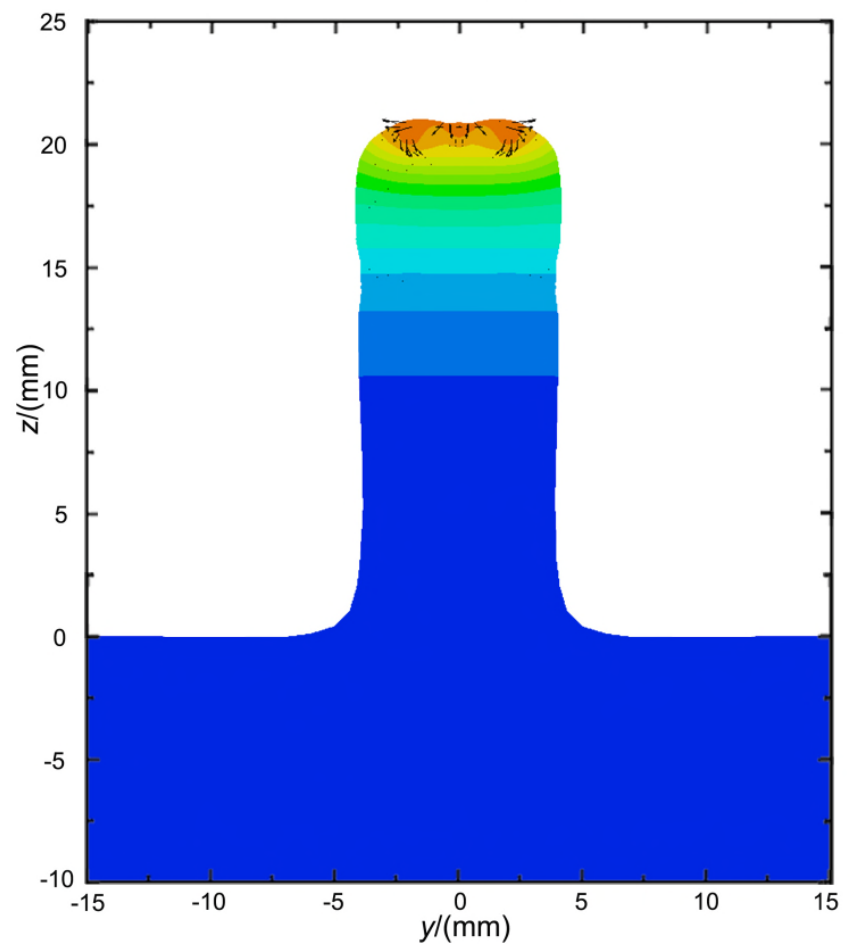

(b)

$T /(\mathrm{K})$

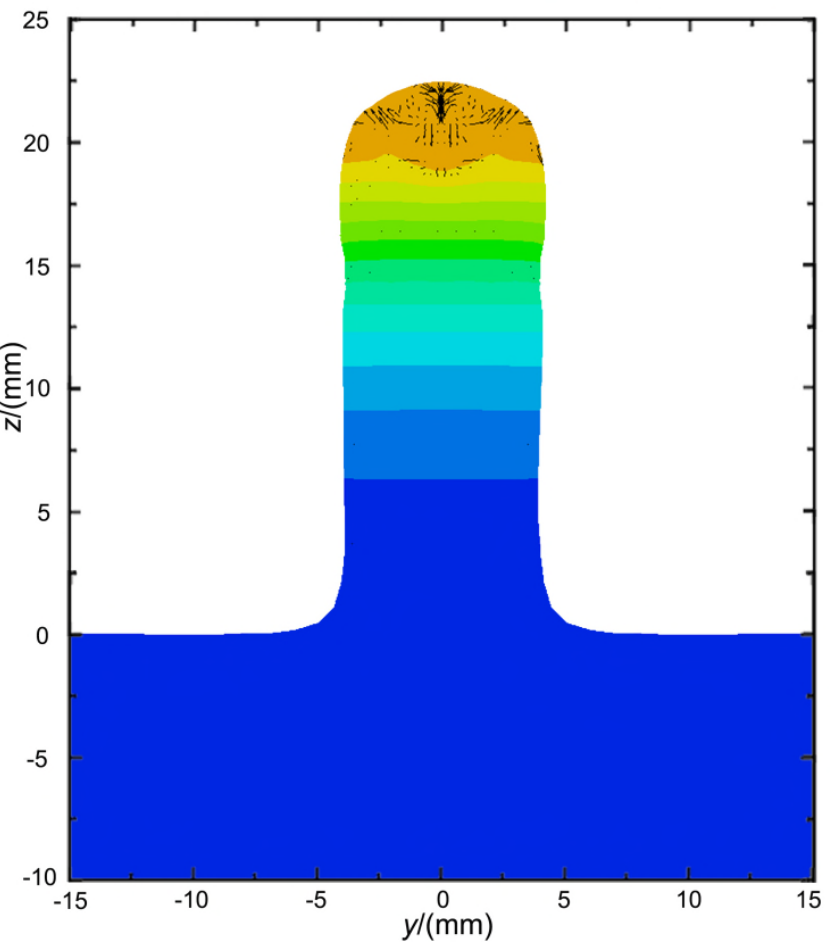

Fig.12. Temperature profiles at $t=4 \mathrm{~s}$ of the $1^{\text {st }}$ layer deposition on different transverse cross-sections: (a) $\mathrm{x}=30 \mathrm{~mm}$ (current arc center location); (b) $\mathrm{x}=20 \mathrm{~mm}$.

As the $21^{\text {st }}$ layer is deposited on the top of a thin wall, the molten pool completely loses support from the sides, and the bead profile is largely related to surface tension support. The other impact of zero side support is a different depressed region shape. Comparing Fig. 12(a), Fig.13 with Fig. 7(a) and Fig. 10(a), it can be 
seen that the depressed region of $21^{\text {st }}$ layer is no longer valley-shaped. Because the arc shear stress is pushing liquid flow outward and the liquid has no side support, the depressed region is almost flat in the Y direction.

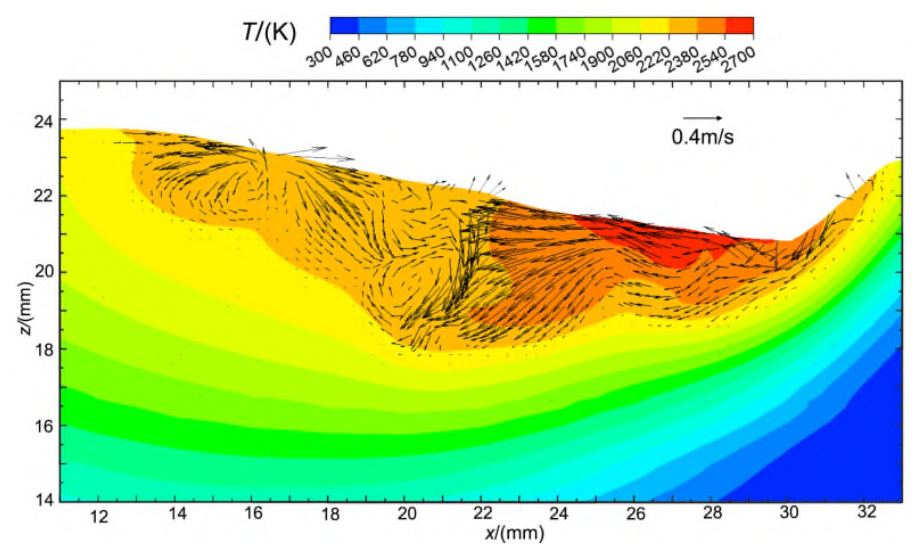

Fig.13. Temperature and fluid flow field on the longitudinal cross-section $(y=0)$ at $t=4 \mathrm{~s}$ of the $21^{\text {st }}$ layer deposition.

The molten pool can be divided into two parts: the rear and the front parts. The front part of molten pool is 6-7 $\mathrm{mm}$ around the arc center where the fluid flow is dominated by arc and Marangoni forces. The rear part is comparatively far from the arc center, the arc forces and temperature gradient become small. In the absence of side support, the molten pool at the rear part is mainly shaped by surface tension and gravity. Fig. 12(b) shows temperature and fluid flow fields on a cross-section of the rear part. It can be seen that the bottom of molten pool and all other isothermal lines are basically flat in the $\mathrm{Y}$ direction.

The flat isothermal lines have two causes. The first is that the molten pool surface under the arc center is almost flat in the Y direction as well, as shown in Fig 12 (a). The second is that conduction is the primary method of heat dissipation compared to convection and radiation during deposition. If convection and radiation losses were significant compared with conduction, the outer walls would be cooler than the inner which would mean curved isothermal lines.

Since conduction is the dominant method of heat dissipation, the original material volume, which acts as a heat sink, plays an important role in determining the size and volume of molten pool. Under the condition of constant heat input and wire feeding, the $1^{\text {st }}$ layer deposition produces the smallest molten pool as it is surrounded by cold material, while the $21^{\text {st }}$ layer has the largest molten pool due to narrow heat conduction channel.

\subsection{Comparison with experiments}

The comparison of the deposited bead profile between the simulated and the experimental results is shown in 
Fig. 14. The experimental profiles shown in Fig.14 (a), (c) and (e) correspond to the cross-sectional planes at $\mathrm{x}=30 \mathrm{~mm}$ (midpoint) of $1^{\text {st }}, 2^{\text {nd }}$ and $21^{\text {st }}$ deposition, respectively. The simulated profiles shown in Fig. 14 (b), (d) and (f) correspond to the temperature distribution on $\mathrm{x}=30 \mathrm{~mm}$ plane at $8.5 \mathrm{~s}(0.5 \mathrm{~s}$ after the ending of deposition) of $1^{\text {st }}, 2^{\text {nd }}$ and $21^{\text {st }}$ deposition, respectively. The simulated profile lines are extracted and shown as red lines in experimental pictures for better comparison. In general, the simulated results are in fair agreement with experiments. In the cases of $1^{\text {st }}$ and $2^{\text {nd }}$ layers, the simulations predict a flatter profile and larger width. This could be due to an inherent defect of porosity enthalpy method. As mentioned above, this widely-used method considers solid as liquid with a momentum sink term. However, some small movement on the surface of solid part can't be completely eliminated with this method, which results in the flatter profile. In the case of $21^{\text {st }}$ layer deposition, the simulated profile has a similar shape of top surface to the experimental profile. Once again the simulated width is slightly larger, but the prediction error is less than $10 \%$.
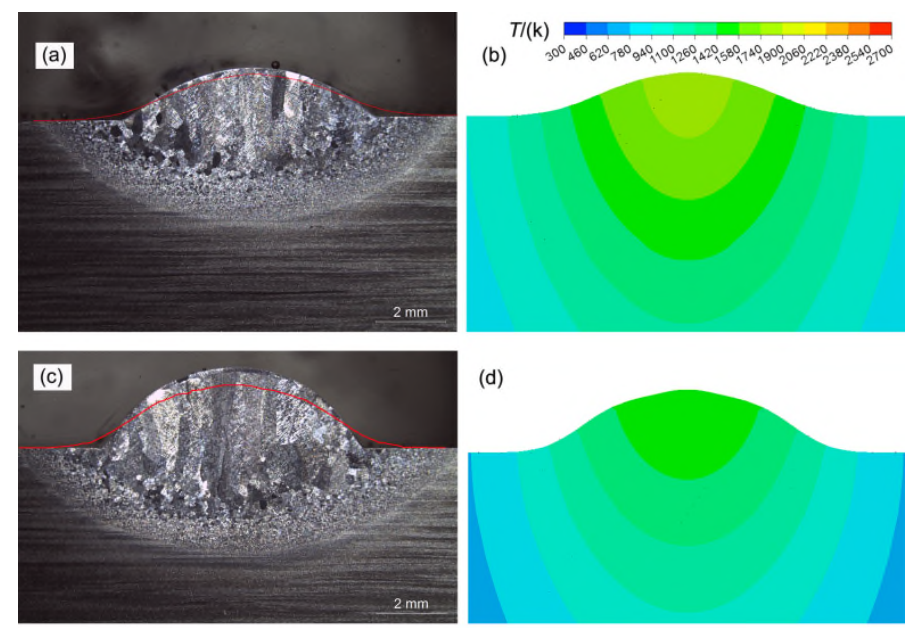

(e)

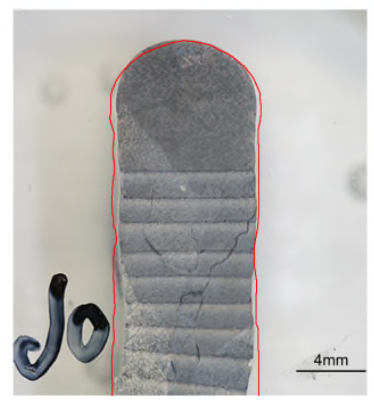

(f)

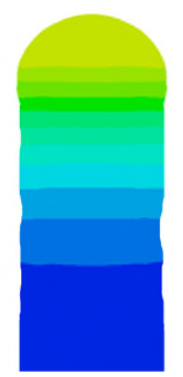

Fig.14. Comparison of cross-sectional profiles on $\mathrm{x}=30 \mathrm{~mm}$ plane: experimental profiles of (a) $1^{\text {st }}$ layer, (c) $2^{\text {nd }}$ layer and (e) $21^{\text {st }}$ layer; simulated profiles at $8.5 \mathrm{~s}$ of (b) $1^{\text {st }}$ layer, (d) $2^{\text {nd }}$ layer and (f) $21^{\text {st }}$ layer.

During the solidification of Ti-6Al-4V in WAAM process, the high temperature $\beta$-grains (bcc) grow epitaxially, columnar can extend through the entire wall, which results in characteristic anisotropic mechanical properties [6]. Fig. 14(e) shows 4 of these large $\beta$-prior beta grains that are several mm large. Upon further 
cooling below the $\beta$-transus of $1268 \mathrm{~K}$, the phase transforms into small $\alpha$-plates, which are only a few $\mu \mathrm{m}$ thick [44]. Also shown are the horizontal isothermal layer bands, which represent the $\alpha$-dissolution temperature [44] of $1021 \mathrm{~K}$ for Ti-6Al-4V, which is good agreement with the predicted peak temperature in Fig. 14(f). Unfortunately no other characteristic features, such as the fusion boundary or the $\beta$-transus temperature, can typically be identified in optical microstructural analysis. So the bright layer band $(1021 \mathrm{~K})$ is the only landmark the microstructure offers for thermal validation.

The comparison of deposited bead size and molten pool size between the simulated and experimental results are shown in Table 4. As for experimental values, the width and layer height of the $1^{\text {st }}$ and $2^{\text {nd }}$ were measured with high accuracy on cross-sectional microscopic images as shown in Fig. 14 (a) and (b); the width and layer height of the $21^{\text {st }}$ layer were obtained measured using caliper and height gauge, respectively, during the deposition process; the depth of molten pool in the $1^{\text {st }}$ layer deposition were measured by analyzing the Fig. 14(a), the bottom of columnar grain was considered as the melting line of molten pool. However, the depths of molten pool in the $2^{\text {nd }}$ and $21^{\text {st }}$ layer are impossible to determine on metallographic images. So these two values are absent.

The rear length of molten pool refers to the distance from arc center to the end of molten pool. This value was measured on the images captured by the process camera. Fig. 15 is the diagram for the measurement of the rear length of molten pool at $4.0 \mathrm{~s}$ in the $21^{\text {st }}$ layer deposition. The image size scale was determined in advance of the $21^{\text {st }}$ layer deposition by observing ruler with camera. The boundary of the molten pool was identified based on the variation of contrast and the ripples on solidified surface.

Table 4 The simulated and experimental results of deposited bead and molten pool shape dimensions

\begin{tabular}{|c|c|c|c|c|c|c|c|}
\hline \multirow{2}{*}{\multicolumn{2}{|c|}{ Dimensions (Unit/mm) }} & \multicolumn{2}{|c|}{$1^{\text {st }}$ Layer } & \multicolumn{2}{|c|}{$2^{\text {nd }}$ Layer } & \multicolumn{2}{|c|}{$21^{\text {st }}$ Layer } \\
\hline & & Experiment & Simulation & Experiment & Simulation & Experiment & Simulation \\
\hline \multirow{2}{*}{$\begin{array}{l}\text { Deposited } \\
\text { bead }\end{array}$} & Width & 7.48 & 8.25 & 7.73 & 8.60 & 7.96 & 8.90 \\
\hline & $\begin{array}{l}\text { Layer } \\
\text { Height }\end{array}$ & 1.40 & 1.33 & 0.96 & 0.87 & 0.93 & 0.84 \\
\hline \multirow{3}{*}{$\begin{array}{l}\text { Molten pool } \\
(t=4 \mathrm{~s})\end{array}$} & Width & 7.48 & 8.13 & 7.73 & 8.50 & 7.96 & 8.90 \\
\hline & Depth & 1.70 & 3.83 & l & 3.41 & / & 6.75 \\
\hline & Rear Length & 10.26 & 10.87 & 10.78 & 10.75 & 16.60 & 17.80 \\
\hline
\end{tabular}




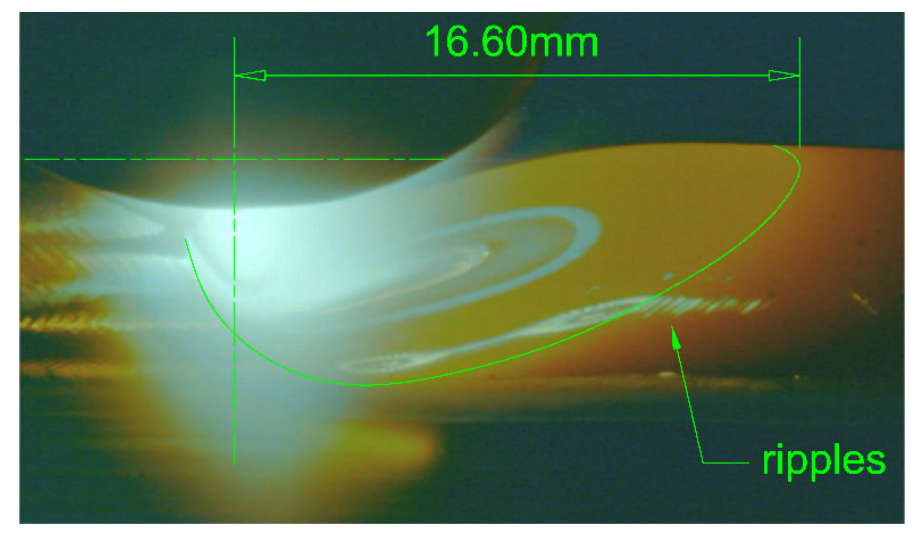

Fig. 15. Side view of the molten pool at $4.0 \mathrm{~s}$ of the $21^{\text {st }}$ layer deposition

The simulated values were calculated by using user defined function in FLUENT. It can be seen in Table 4 that the predicted results are in good agreement with those in the experiments. The simulations show acceptable accuracy in predicting the length of molten pool, the width and layer height of deposited bead. In both simulation and experiment, the width of deposited bead tends to increase with layer number, while the layer height has the opposite trend. It should be noted that the layer height decreases by about $30 \%$ from the $1^{\text {st }}$ layer to $2^{\text {nd }}$ layer, but decrease $3 \%$ from the $2^{\text {nd }}$ layer to $21^{\text {st }}$ layer. According to previous studies of WAAM $[5,42]$, the width and layer height of deposited bead change fast during the first few layers (no more than 4 layers) and remain almost unchanged afterwards. However, the change of molten pool length doesn't follow the pattern.

As one of the earliest CFD studies regarding the WAAM process, the present study focus on the morphology prediction of the molten pool and deposited bead in the typical scenario of multilayer deposition. The above comparison has demonstrated the acceptable prediction accuracy. In future, the presented model will be further validated with experiments and be extended for more complex deposition scenarios that involve such as overlapping, oscillation path, overhang structure, variable deposition parameters and etc.. Many experiments can be eliminated in the process thanks to the model. Having included the critical temperature and fluid flow fields, this model is also expected to be useful in assisting the studies of microstructure control, and imperfection reduction as well.

\section{Conclusions}

A three-dimensional transient model was developed to quantitatively analyze the temperature and fluid flow evolution during the multilayer deposition of PAW-based Wire and Arc Additive Manufacturing process. By comparing and discussing the computational and experimental results of $1^{\text {st }}, 2^{\text {nd }}$ and $21^{\text {st }}$ layer depositions, the following conclusions can be made. 
(1) The modified heat source model proposed in this study proves to be an adaptive volumetric reformulation of double elliptic surface heat source. This heat source model shows better adaptability to free surface deformation than conventional double ellipsoidal heat source model, as the total heat input remains constant regardless of the dynamically changing molten pool surface.

(2) The fluid flow pattern is formed in the front part of molten pool and mainly controlled by Marangoni and arc forces. In the studied deposition case, since a small plasma gas flow rate is used, the arc shear stress is small. Thus, the main fluid flow is clockwise direction driven by Marangoni force.

(3) During deposition, conduction is the dominant method of heat dissipation compared to convection and radiation to the air. Heat conduction channel is reduced when deposition layer number increase, thereby resulting in larger molten pool. The deposition condition and the size of molten pool remain unchanged after the deposited part is sufficiently high.

(4) In high layer deposition where side support is absent, the bottom of molten pool in the back part is almost flat in the $\mathrm{Y}$ direction. The profile is determined by static pressure caused by gravity and surface tension pressure, so the profile of deposited bead is nearly circular.

(5) By comparing with experiments, the numerical model is validated to be capable of predicting the shape and size of deposited bead. Under the condition of constant heat input and wire feeding, the width of the deposited bead has an increasing trend, and the layer height has a decreasing trend when the layer number increases. However, the change to the width and layer height is slow after the $2^{\text {nd }}$ layer.

\section{Acknowledgments}

This work is supported by the National Natural Science Foundation of China (Grant No. 51505210 and 51705287) and the Research Foundation of Education Bureau of Hunan Province, China (Grant No. 15C1180). This work is also a collaborative study supported by the WAAMMat consortium and a Chinese Scholarship Council project (Grant No. 201608430039).

\section{Conflict of Interest}

The authors declare that they have no conflict of interest. 


\section{References}

[1] J. J. Lewandowski, M. Seifi, Metal additive manufacturing: a review of mechanical properties. Annu. Rev. Mater. Res. 46 (2016) 151-186.

[2] W. E. Frazier, Metal additive manufacturing: a review. J. Mater. Eng. Perform. 23 (2014) 1917-1928.

[3] C. Yan, L. Hao, A. Hussein, P. Young, D. Raymont, Advanced lightweight 316L stainless steel cellular lattice structures fabricated via selective laser melting, J. Mater. 55 (2014) 533-541.

[4] D. Ding, Z. Pan, D. Cuiuri, H. Li, Wire-feed additive manufacturing of metal components: technologies, developments and future interests. Int. J. of Adv. Manuf. Technol. 81 (2015) 465-481.

[5] S.W. Williams, F. Martina, A.C. Addison, J. Ding, G. Pardal, P. Colegrove, F. Martina, A.C. Addison, J. Ding, G. Pardal, P. Colegrove, Wire+ arc additive manufacturing. Mater. Sci. Technol., 32 (2016) 641647.

[6] F. Wang, S. Williams, P. Colegrove, A. A. Antonysamy, Microstructure and mechanical properties of wire and arc additive manufactured Ti-6Al-4V. Metall. Mater. Trans. A, 44 (2013) 968-977.

[7] J.J. Lin, Y.H. Lv, Y.X. Liu, B.S. Xu, Z. Sun, Z.G. Li, Y.X. Wu, Microstructural evolution and mechanical properties of Ti-6Al-4V wall deposited by pulsed plasma arc additive manufacturing, Mater. Des. 102 (2016) 30-40.

[8] D. Ding, Z. Pan, D. Cuiuri, H. Li, A multi-bead overlapping model for robotic wire and arc additive manufacturing ( WAAM ), Robot. Comput. Integr. Manuf. 31 (2015) 101-110.

[9] D. Ding, Z. Pan, D. Cuiuri, H. Li, S. Van Duin, N. Larkin, Bead modelling and implementation of adaptive MAT path in wire and arc additive manufacturing, Robot. Comput. Integr. Manuf. 39 (2016) $32-42$.

[10] J. Xiong, G. Zhang, J. Hu, L. Wu, Bead geometry prediction for robotic GMAW-based rapid manufacturing through a neural network and a second-order regression analysis. J. Intell. Manuf. 25 (2014) $157-163$.

[11] Q. Wu, J. Lu, C. Liu, H. Fan, X. Shi, J. Fu, S. Ma, Effect of Molten Pool Size on Microstructure and Tensile Properties of Wire Arc Additive Manufacturing of Ti-6Al-4V Alloy. Materials, 10(2017), 749.

[12] M.J. Bermingham, D. Kent, H. Zhan, D.H. Stjohn, M.S. Dargusch, ScienceDirect Controlling the microstructure and properties of wire arc additive manufactured $\mathrm{Ti}-6 \mathrm{Al}-4 \mathrm{~V}$ with trace boron additions, Acta Mater. 91 (2015) 289-303. 
[13] O. Yilmaz, A.A. Ugla, (2017). Microstructure characterization of SS308LSi components manufactured by GTAW-based additive manufacturing: shaped metal deposition using pulsed current arc. Int. J. of Adv. Manuf. Technol. 89(2017), 13-25.

[14] X. Zhou, H. Zhang, G. Wang, X. Bai, Three-dimensional numerical simulation of arc and metal transport in arc welding based additive manufacturing, Int. J. Heat Mass Transf. 103 (2016) 521-537.

[15] M. Tanaka, H. Terasaki, M. Ushio, J.J. Lowke, A unified numerical modeling of stationary tungsten-inertgas welding process. Metall. Mater. Trans. A. 33(2002), 2043-2052.

[16] A. B. Murphy, M. Tanaka, K. Yamamoto, S. Tashiro, T. Sato, J. J. Lowke, Modelling of thermal plasmas for arc welding: the role of the shielding gas properties and of metal vapour. J. Phys. D: Appl. Phys. 42(2009), 194006.

[17] A. Traidia, F. Roger, Numerical and experimental study of arc and weld pool behaviour for pulsed current GTA welding, Int. J. Heat Mass Transf. 54 (2011) 2163-2179.

[18] X. Wang, D. Fan, J. Huang, Y. Huang, A unified model of coupled arc plasma and weld pool for double electrodes TIG welding, J. Phys. D: Appl. Phys. 47(2014) 202-275.

[19] J. Hu, H.L. Tsai, Heat and mass transfer in gas metal arc welding. Part I: The arc, Int. J. Heat Mass Transf. 50 (2007) 833-846.

[20] J. Hu, H.L. Tsai, Heat and mass transfer in gas metal arc welding. Part II: The metal, Int. J. Heat Mass Transf. 50 (2007) 808-820.

[21] C. S. Wu, J. Chen, Y. M. Zhang, Numerical analysis of both front- and back-side deformation of fullypenetrated GTAW weld pool surfaces, Comput. Mater. Sci. 39 (2007) 635-642.

[22] J. Pan, S. Hu, L. Yang, D. Wang, Investigation of molten pool behavior and weld bead formation in VPGTAW by numerical modelling, Mater. Des. 111 (2016) 600-607.

[23] J. Chen, C. Shwenk, C. S. Wu, M. Rethmeiera, Predicting the influence of groove angle on heat transfer and fluid flow for new gas metal arc welding processes, Int. J. Heat Mass Transf. 55(2011) 102-111.

[24] M.H. Cho, D.F. Farson, Understanding Bead Hump Formation in Gas Metal Arc Welding Using a Numerical Simulation, Metall. Mater. Trans. B, 38 (2007) 305-319.

[25] J. Hu, H. Guo, H. L. Tsai, Weld pool dynamics and the formation of ripples in 3D gas metal arc welding, Int. J. Heat Mass Transf. 51(2008)2537-2552.

[26] J. W. Liu, Z. H. Rao, S. M. Liao, H. L. Tsai, Numerical investigation of weld pool behaviors and ripple 
formation for a moving GTA welding under pulsed currents, Int. J. Heat Mass Transf, 91 (2015) 9901000.

[27] H. Guo, J. Hu, H.L. Tsai, Formation of weld crater in GMAW of aluminum alloys, Int. J. Heat Mass Transf. 52 (2009) 5533-5546.

[28] O. Desmaison, M. Bellet, G. Guillemot, A level set approach for the simulation of the multipass hybrid laser / GMA welding process, Comput. Mater. Sci. 91 (2014) 240-250.

[29] X.J. Wang, C.S. Wu, MA Chen, Numerical simulation of weld pool keyholing process in stationary plasma arc welding, Acta. Metall. Sin. 46 (2010) 984-90.

[30] J.H. Sun, C.S. Wu, M.A. Chen, Numerical Analysis of Transient Temperature Field and Keyhole Geometry in Controlled Pulse Key- Holing Plasma Arc Welding, Numer. Heat Transfer, Part A: Appl. 64 (2013) 416-434.

[31] T. Zhang, C. S. Wu, Y. Feng, Numerical analysis of heat transfer and fluid flow in keyhole plasma arc welding. Numer. Heat Transfer, Part A: Appl. 60 (2011) 685-698.

[32] X. Jian, C.S. Wu, Numerical analysis of the coupled arc-weld pool-keyhole behaviors in stationary plasma arc welding, Int. J. Heat Mass Transf. 84 (2015) 839-847.

[33] V.R. Voller, A.D. Brent, C. Prakash, The modelling of heat, mass and solute transport in solidification systems. Int. J. Heat Mass Transf, 32 (1989) 1719-1731.

[34] K. C. Tsao, C. S. Wu, Fluid flow and heat transfer in GMA weld pools. Weld. J. 67 (1988) 70s-75s.

[35] X. Meng, G. Qin, X. Bai, Z. Zou, Numerical analysis of undercut defect mechanism in high speed gas tungsten arc welding, J. Mater. Process. Technol. 236 (2016) 225-234.

[36] S. W. Campbell, A. M. Galloway, N. A. McPherson, Arc pressure and fluid flow during alternating shielding gases. Part 2: arc force determination, Sci. Technol. Weld. Joining. 18 (2013) 597-602.

[37] J. U. Brackbill, D. B. Kothe, C.Zemach, A continuum method for modeling surface tension, J. of comput. Phys. 100 (1992) 335-354.

[38] Nishi, S., Kusamichi, T., \& Onoye, T. (2007). Arc voltage and heat efficiency during plasma arc melting of titanium. Isij International, 35(2), 114-120.

[39] X. Bai, H. Zhang, G. Wang, Improving prediction accuracy of thermal analysis for weld-based additive manufacturing by calibrating input parameters using IR imaging. Int. J. of Adv. Manuf. Technol., 69 (2013) 1087-1095. 
[40] C. Panwisawas, B. Perumal, R.M. Ward, N. Turner, R.P. Turner, J.W. Brooks, H.C. Basoalto, Keyhole formation and thermal fluid flow-induced porosity during laser fusion welding in titanium alloys : Experimental and modelling, Acta. Mater. 126 (2017) 251-263.

[41] M. Boivineau, C. Cagran, D. Doytier, V. Eyraud, M. Nadal, B. Wilthan, G. Pottlacher, Thermophysical Properties of Solid and Liquid Ti-6Al-4V Alloy, Int. J. Thermophys. 27 (2006) 507-529.

[42] I.Egry, D. Holland-Moritz, R. Novakovic, E. Ricci, R. Wunderlich, N. Sobczak, Thermophysical properties of liquid AlTi-based alloys, Int. J. Thermophys. 31(2010) 949-965.

[43] P. M. Sequeira Almeida, Process control and development in wire and arc additive manufacturing, $\mathrm{PhD}$ thesis, Cranfield University, Cranfield, UK, 2012.

[44] F. Martina, P. A.Colegrove , S. W. Williams, J. Meyer, Microstructure of interpass rolled wire + arc additive manufacturing ti-6al-4v components, Metall. Mater. Trans. A, 46 (2015) 6103-6118. 
Numerical analysis of heat transfer and fluid flow in multilayer deposition of

PAW-based wire and arc additive manufacturing

\section{Bai, Xingwang}

Elsevier

Xingwang Bai, Paul Colegrove, Jialuo Ding, et al., Numerical analysis of heat transfer and fluid flow in multilayer deposition of PAW-based wire and arc additive manufacturing. International Journal of Heat and Mass Transfer, Volume 124, September 2018, Pages 504-516 https://doi.org/10.1016/j.jheatmasstransfer.2018.03.085 Downloaded from Cranfield Library Services E-Repository 